\title{
Identification of nitric oxide reductase activity in Rhodobacter capsulatus: the electron transport pathway can either use or bypass both cytochrome $c_{2}$ and the cytochrome $b c_{1}$ complex
}

\author{
Louise C. Bell, David J. Richardson $\dagger$ and Stuart J. Ferguson* \\ Department of Biochemistry, University of Oxford, South Parks Road, Oxford OX13QU, UK
}

(Received 28 June 1991; revised 27 November 1991; accepted 5 December 1991)

\begin{abstract}
Several strains of $\boldsymbol{R}$ hodobacter capsulatus have been shown to possess a nitric oxide reductase activity (reaction product nitrous oxide) after anaerobic phototrophic growth, but not after aerobic growth. The reductase is associated with the cytoplasmic membrane and electrons can reach the enzyme via the cytochrome $b c_{1}$ complex. However, use of appropriate strains has shown that neither the latter, cytochrome $c_{2}$ nor cytochrome $c^{\prime}$ is essential for the reduction of nitric oxide. Inhibition by myxothiazol of nitric oxide reduction in a strain that lacks a cytochrome $c_{2}$ establishes that in phototrophically grown $R$. capsulatus the cytochrome $b c_{1}$ complex is able to transfer electrons to an acceptor that is alternative to cytochrome $c_{2}$. Electron transport to nitric oxide from NADH or succinate generated a membrane potential. When isoascorbate plus 2,3,5,6-tetramethyl-p-phenylenediamine (DAD) was the electron donor a membrane potential was not generated. This observation implies that nitric oxide is reduced at the periplasmic surface of the membrane and that the reductase is not proton translocating.
\end{abstract}

\section{Introduction}

Recent experiments (Goretski \& Hollocher, 1988; Carr et al., 1989; Zafiriou et al., 1989) have provided strong evidence for nitric oxide being a free intermediate within the overall process of bacterial denitrification. A discrete nitric oxide reductase that contains $b$ and $c$-type haems has been identified in Pseudomonas stutzeri and Paracoccus denitrificans (Heiss et al., 1989; Carr \& Ferguson, $1990 a$ ).

Certain strains of the photosynthetic bacterium Rhodobacter capsulatus are able to catalyse the reduction of some of the oxy-species of nitrogen that participate in the denitrification process. Thus the possession of a nitrate reductase, periplasmic in strains. AD2 and N22DNAR ${ }^{+}$(McEwan et al., 1984) but membranebound in strain BK5 (Ballard et al., 1990), and a periplasmic nitrous oxide reductase have been reported

* Author for correspondence. Tel. (0865) 275240; fax (0865) 275259.

† Present address: School of Biological Sciences, University of East Anglia, Norwich NR4 7TJ, UK.

Abbreviations: DAD, 2,3,5,6-tetramethyl-p-phenylenediamine; HOQNO, 2-n-heptyl-4-hydroxyquinoline- $N$-oxide.
(McEwan et al., 1985; Ferguson et al., 1987). Recently, it has been shown that in strain AD2 the nitrate reductase activity is lost in plasmid-deficient isolates (Willison, 1990). Some strains of $R$. capsulatus, e.g. 37b4, do not possess any of these activities (Kelly et al., 1988). Those strains possessing a nitrate reductase accumulate nitrite because a reductase for the latter is not present (Ferguson et al., 1987). The recent identification of a bacterial nitric oxide reductase raises the question as to whether at least some strains of $R$. capsulatus have this enzyme. The possession of the enzymes for reducing some of the oxyspecies of nitrogen suggests that $R$. capsulatus encounters such molecules in its natural habitats and that therefore nitric oxide reductase may be present. Furthermore, the toxicity of nitric oxide, coupled with the evidence of its extensive production in some environments (Rende $e t$ al., 1989), suggests that it may be advantageous to possess nitric oxide reductase activity. The present paper describes strains of $R$. capsulatus that possess nitric oxide reducing activity, and, by analysis of certain mutant strains, provides evidence for the nature of the electron transport chain that terminates in this enzyme. In addition, some general conclusions about a multiplicity of electron transport pathways in $R$. capsulatus can be made. 
Table 1. Strains of Rhodobacter capsulatus used in this study

\begin{tabular}{|c|c|c|}
\hline Strain & Characteristics* & $\begin{array}{l}\text { Source and/or } \\
\text { referencet }\end{array}$ \\
\hline $\begin{array}{l}\text { MT1131 } \\
\text { MTG4/S4 }\end{array}$ & $\begin{array}{l}\text { Green mutant; DNAR }{ }^{-} \text {NOSR }^{+} \\
\text {Cyt. } c_{2} \text { deletion mutant isolated from MT1131; DNAR-NOSR-Km }\end{array}$ & $\begin{array}{l}\text { F. Daldal }{ }^{a} \\
\text { Daldal } \text { et al. (1989) }\end{array}$ \\
\hline $\begin{array}{l}\text { MTCBC1 } \\
\text { MTGS18 }\end{array}$ & $\begin{array}{l}\text { Cyt. } b c_{1} \text { deletion mutant isolated from MT1131; DNAR-NOSR+ } \text { Pho }^{-} \mathrm{Sp}^{\mathrm{r}} \\
\text { Cyt. } c_{2} \backslash b c_{1} \text { deletions isolated from MTG4/S4; DNAR } \text { NOSR-Pho- }^{-} \mathbf{K m}^{r} \mathbf{S p}^{r}\end{array}$ & Daldal et al. (1987) \\
\hline $\begin{array}{l}\text { BK5 } \\
\text { AD2 }\end{array}$ & $\begin{array}{l}\text { Wild-type strain; DNAR }{ }^{+} \text {NOSR }^{+} \\
\text {Wild-type strain; DNAR }{ }^{+} \text {NOSR }^{+} \text {Rif }^{r}\end{array}$ & J. H. Klemme ${ }^{b}$ \\
\hline $\begin{array}{l}10 a .2 .3 \\
\text { N22 } \\
\text { N22DNAR+ } \\
37 \text { b4 } \\
\text { H123 } \\
\text { Z-1 } \\
\text { M5 }\end{array}$ & 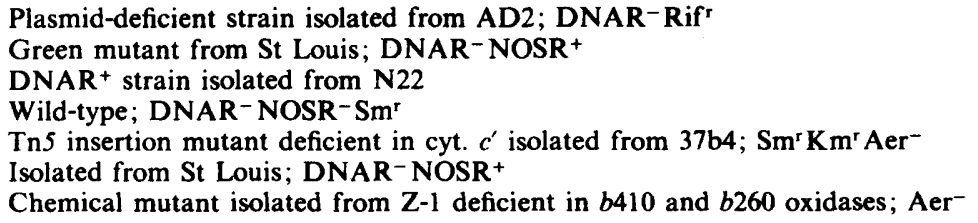 & $\begin{array}{l}\text { Willison }(1990)^{c} \\
\text { O. T. G. Jones } \\
\text { McEwan et al. }(1982) \\
\text { H. Hudige } \\
\text { Hudig et al. }(1986) ; \text { H. Hudige } \\
\text { Marrs \& Gest (1973); B. Marrs }{ }^{f} \\
\text { Marrs \& Gest (1973) }\end{array}$ \\
\hline
\end{tabular}

* $\mathrm{Km}^{\mathrm{r}}$, kanamycin resistance; $\mathrm{Sp}^{\mathrm{r}}$, spectinomycin resistance; $\mathrm{Sm}^{\mathrm{r}}$, streptomycin resistance; $\mathbf{R i f}^{\mathrm{r}}$, rifampicin resistance. DNAR, dissimilatory nitrate reduction; NOSR, nitrous oxide reduction; Pho, phototrophic growth; Aer, aerobic growth.

$\dagger$ Addresses: $a$, University of Philadelphia, USA; $b$, University of Bonn, Germany; $c$, CNRS, Grenoble, France; $d$, University of Bristol, UK ; $e$, University of Freiburg, Germany; $f$, Dupont, Wilmington, USA.

\section{Methods}

$R$. capsulatus strains. The strains used in this study are listed in Table 1. Cells were grown phototrophically on a RCV medium as described by Weaver et al. (1975) but with 30 mM-sodium succinate substituted for malate. Antibiotics were added to the medium where appropriate (Daldal et al., 1987). The medium for $R$. capsulatus strains Z-1 and M5 was sparged with argon before growth since strain M5 lacks oxidase activity and it has been reported that oxygen represses the synthesis of the photosynthetic apparatus. Strains MTCBC1 and MTGS18, which are unable to grow phototrophically (Heiss et al., 1989), were grown aerobically to mid-exponential phase and then incubated anaerobically in the dark for $12 \mathrm{~h}$ with the medium supplemented with $10 \mathrm{~mm}$-glucose and $25 \mathrm{mM}-\mathrm{NaCl}$.

Nitric oxide reduction. This was measured using a nitrous oxide electrode sensitive to both nitric oxide and nitrous oxide as previously described (Carr et al., 1989; Bell \& Ferguson, 1991). All measurements were performed at $30^{\circ} \mathrm{C}$. In some experiments nitric oxide reduction was measured in the presence of one or both of the electron transport inhibitors, 2-n-heptyl-4-hydroxyquinoline- $N$-oxide (HOQNO) and myxothiazol. The non-physiological electron donor sodium isoascorbate in conjunction with 2,3,5,6-tetramethyl-p-phenylenediamine (DAD) was used in certain experiments.

Membrane vesicles. These were prepared by lysing spheroplasts as described by Burnell et al. (1975) except that 3 mM-EDTA was included in the medium for preparing the spheroplasts. Membrane potentials were measured from the electrochromic response of the endogenous carotenoid pigments at either $528-511 \mathrm{~nm}$ or $503-487 \mathrm{~nm}$ (for green mutants) using an Aminco DW2000 spectrophotometer in the dual wavelength mode. Cell protein was determined by lysing the cells in $0 \cdot 1 \mathrm{M}-\mathrm{NaOH}$ at $100{ }^{\circ} \mathrm{C}$ before assaying by the Lowry method (with BSA as standard).

\section{Results}

As explained in previous publications (Carr et al., 1989; Bell \& Ferguson, 1991), a silver cathode Clark-type

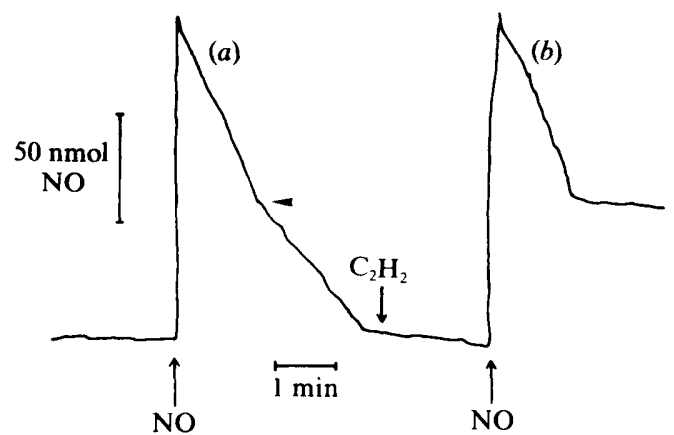

Fig. 1. Reduction of nitric oxide by cells of $R$. capsulatus MT1131. The reaction chamber contained $2 \mathrm{ml}$ of RCV medium containing $30 \mathrm{mM}$ sodium succinate rather than malate, $5.5 \mathrm{mg}$ cell protein, 4 units glucose oxidase, 50 units catalase and $16 \mathrm{~mm}$-D-glucose. Once the solution was anaerobic, additions of nitric oxide $(75 \mu \mathrm{M}$ final concentration) and acetylene (1 mM concentration) were made as shown. ( $\triangleleft)$ marks the transition in record $(a)$ from the first to the second phase. Following the reduction of nitrous oxide, and both before and after the addition of acetylene, there is a slight drift on the base line response of the electrode.

electrode responds to both nitric and nitrous oxides, with the former being detected at slightly higher sensitivity than the latter. Fig. 1 shows the response of such an electrode when nitric oxide was introduced into a reaction chamber containing cells of $R$. capsulatus strain MT1131. The first phase of the response in record (a) corresponds to the reduction of nitric oxide and the second phase to the reduction of nitrous oxide, as established by the prevention of the second phase by acetylene in record $(b)$. Acetylene specifically inhibits nitrous oxide reductase in denitrifying bacteria 
Table 2. Effects of inhibitors of electron transport on rates of electron transport to nitric oxide in cells of $R$. capsulatus strain MT113l and mutant MTG4/S4

A reaction chamber fitted with a Clark-type silver cathode electrode contained, in a total volume of $2 \mathrm{ml}: \mathrm{RCV}$ medium with $30 \mathrm{mM}$-sodium succinate instead of malate, 4 units glucose oxidase, 50 units catalase, $16 \mathrm{mM}$-D-glucose and cells of $\boldsymbol{R}$. capsulatus. Once the reaction mixture was anaerobic nitric oxide was added to a final concentration of $75 \mu \mathrm{M}$. Other additions were made as shown. The temperature was $30^{\circ} \mathrm{C}$ and light was excluded from the chamber. The rates given are typical data representing three experiments. There was a variation between different batches of cells of $\pm 5 \mathrm{nmol} \mathrm{min} \mathrm{mg}^{-1}(\mathrm{mg} \text { protein })^{-1}$. ND, Not determined.

\begin{tabular}{lcc}
\hline \hline \multicolumn{1}{c}{ Strain } & $\begin{array}{c}\text { Nitric oxide reductase activity } \\
{\left[\text { [mol min } \text { (mg protein) }^{-1}\right]}\end{array}$ \\
\cline { 2 - 3 } & MT1131 & MTG4/S4 \\
\hline $\begin{array}{l}\text { Additions } \\
\text { None }\end{array}$ & 20 & 15 \\
$3 \mu \mathrm{M}-$ Myxothiazol & 9 & 7 \\
$3 \mu \mathrm{M}-$ Myxothiazol $+20 \mu \mathrm{M}-\mathrm{DAD}+0 \cdot 25$ mM-sodium isoascorbate & 21 & 15 \\
$3 \mu \mathrm{M}-$ Myxothiazol $+20 \mu \mathrm{M}-\mathrm{HOQNO}$ & 3 & $\mathrm{ND}$ \\
$3 \mu \mathrm{M}-$ Myxothiazol $+20 \mu \mathrm{M}-\mathrm{HOQNO}+20 \mu \mathrm{M}$-DAD +0.25 mM-sodium isoascorbate & 19 & ND \\
\hline \hline
\end{tabular}

(Balderston et al., 1976; Yoshimura \& Knowles, 1976). It is clear that nitric oxide strongly inhibits the reduction of nitrous oxide and thus rates of nitric oxide reduction can be calculated directly from the first phase of records such as $(a)$ in Fig. 1 ; no correction for concomitant reduction of nitrous oxide is necessary. Similar observations to those in record $(a)$ of Fig. 1 were made with several other strains of $R$. capsulatus. Thus typical rates of nitric oxide reduction were $20 \mathrm{nmol} \mathrm{min}{ }^{-1}(\mathrm{mg} \text { protein })^{-1}$ for both MT1131 (Table 2) and AD2, $30 \mathrm{nmol} \mathrm{min}^{-1}$ (mg protein $)^{-1}$ for both $\mathrm{N} 22$ and N22DNAR ${ }^{+}, 35 \mathrm{nmol}$ $\mathrm{min}^{-1}$ (mg protein) $)^{-1}$ for BK5, and $10 \mathrm{nmol} \mathrm{m^{-1 }}(\mathrm{mg}$ protein $)^{-1}$ for $\mathrm{Z}-1$, all measured under the conditions specified in the legend to Fig. 1. R. capsulatus strain $37 \mathrm{~b} 4$ also reduced nitric oxide with a typical rate of $15 \mathrm{nmol}$ $\min ^{-1}$ (mg protein $)^{-1}$, but the response of the electrode was a single phase [as record $(b)$ in Fig. 1], consistent with the absence of nitrous oxide reductase in this strain (Kelly $e t$ $a l ., 1988$ ). No strain of $R$. capsulatus tested (Table 1) was found to lack nitric-oxide-reducing activity.

There are reports of the non-specific reduction of nitric oxide by oxidase activities (Brudvig et al., 1980). $R$. capsulatus M5 is completely deficient in both the cytochrome $b 410$ and cytochrome $b 260$ oxidase activities (Marrs \& Gest, 1978), but it had a typical nitric oxide

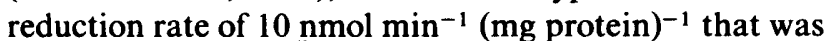
indistinguishable from the parent strain Z-1. In addition, after aerobic growth all tested strains of $R$. capsulatus, which had oxidase activities in the range 50 to $100 \mathrm{nmol}$ $\mathrm{O} \mathrm{min}^{-1}$ (mg protein) $)^{-1}$, did not reduce nitric oxide. Thus it appears very probable that nitric oxide reduction is performed by a discrete reductase. Recent work (Willison, 1990) has indicated that $R$. capsulatus strain 10a.2.3, which has been cured of an endogenous plasmid, no longer has the ability to respire nitrate. This finding prompted enquiry into whether nitric oxide reductase is encoded on this endogenous plasmid. However, the cured strain reduced both nitric and nitrous oxides at rates comparable to the parent $R$. capsulatus strain AD2, indicating that the genes for these activities are not located on the cured plasmid.

Connection of the nitric oxide reductase to the electron transport chain of $R$. capsulatus was established by the observation of a nitric-oxide-dependent electrochromic shift in the absorption maximum of the endogenous carotenoids. The latter is an indicator of cytoplasmic membrane potential. The potential generated after a pulse of mitric oxide was smaller by a factor of two, assuming the linearity of the carotenoid response, than that which was developed upon illumination of cells (not shown). Fractionation of cells into periplasm, cytoplasm and membranes revealed that NADH-, succinate- or isoascorbate/DAD-dependent nitric oxide reduction was associated with the membrane fragments whilst the nitrous oxide reductase activity was released into the periplasm fraction (not shown). As expected on the basis of the fractionation studies, membrane vesicles generated an NADH- and succinate-dependent membrane potential in response to the addition of nitric oxide (Fig. 2). A membrane potential was not observed either in the presence of nitric oxide and isoascorbate/DAD or following addition of nitrous oxide. The latter observation is consistent with loss of the reductase for the latter from membrane vesicles.

Myxothiazol inhibits specifically the cytochrome $b c_{1}$ complex of electron transport chains (Trumpower, 1990). The finding that myxothiazol partially inhibited the reduction of nitric oxide by cells (Table 2 ; data shown for 


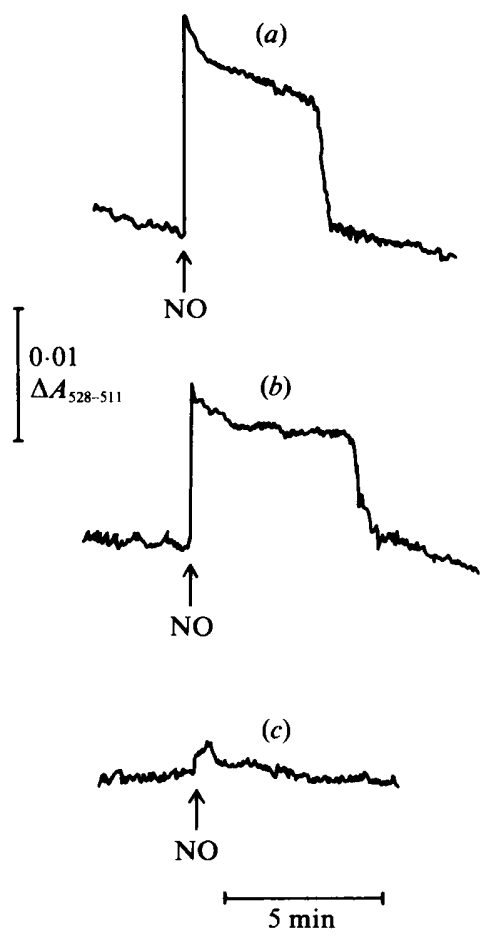

Fig. 2. Electrochromic absorbance changes of the carotenoid pigment of membrane vesicles of $R$. capsulatus strain MT1131 following the addition of $10 \mu \mathrm{M}$-nitric oxide. Vesicles ( $0.4 \mathrm{mg}$ protein) were resuspended in $1.5 \mathrm{ml} \mathrm{10 \% (w/v)} \mathrm{sucrose,} 50 \mathrm{mM}-\mathrm{KCl}, 8 \mathrm{~mm}-\mathrm{MgCl}_{2}, 50 \mathrm{~mm}$ Tricine/KOH, pH 7.4, containing 4 units catalase, 50 units glucose oxidase, and $16 \mathrm{mM}$-D-glucose in a sealed cuvette. The following additions were made: (a) $50 \mu \mathrm{M}-\mathrm{NADH}$; (b) $1 \mathrm{mM}$-sodium succinate; (c) $20 \mu \mathrm{M}$-DAD plus $100 \mu \mathrm{M}$-sodium isoascorbate. Once the suspensions had become anaerobic, and a steady baseline attained, nitric oxide was added.

MT1131 as an example of wild-type cells) thus indicated that electron flow could proceed to nitric oxide reductase via the cytochrome $b c_{1}$ complex. No additional inhibition accompanied introduction of higher concentrations of myxothiazol. Nitric oxide reduction by either cells or vesicles (not shown) was restored following the addition of isoascorbate/DAD which introduces electrons after the site of myxothiazol inhibition. It is notable that the inhibition by myxothiazol was never complete. Similar observations have been made for the reduction of nitrous oxide by $R$. capsulatus (Richardson et al., 1989). In that case it was shown that the cytochrome $b c_{1}$ complex could be bypassed. The same is true for nitric oxide reduction because a mutant that lacked a functional $b c_{1}$ complex ( $R$. capsulatus MTCBC1) was competent in nitric oxide reduction $\left[10 \mathrm{nmol} \mathrm{min}{ }^{-1}(\mathrm{mg}\right.$ protein $)^{-1}$ ] at a rate which was, however, attenuated relative to the parent (MT1131) strain $\left[15 \mathrm{nmol} \mathrm{min}^{-1}\right.$ (mg protein $)^{-1}$ ] under the growth conditions used for
MTCBCl. As expected, and in agreement with previous observations concerning nitrous oxide reduction by $R$. capsulatus MTCBC1 (Richardson et al., 1989), an amount of myxothiazol sufficient to inhibit the cytochrome $b c_{1}$ complex in wild-type cells had no effect on the rate of nitric oxide reduction by $R$. capsulatus MTCBCl. Thus there exists a pathway for electrons that is independent of, and alternative to, the myxothiazolsensitive cytochrome $b c_{1}$ complex. This alternative pathway was sensitive to $20 \mu \mathrm{M}-\mathrm{HOQNO}$ as shown by over $80 \%$ inhibition of nitric oxide reduction in wild-type cells in the presence of both this inhibitor and $3 \mu \mathrm{M}$ myxothiazol (Table 2). The same conclusion could be drawn from the finding that $20 \mu \mathrm{M}-\mathrm{HOQNO}$ gave $90 \%$ inhibition of the nitric oxide reduction in $R$. capsulatus MTCBC1 which lacks a functional cytochrome $b c_{1}$ complex. In both cases the rate of reduction of nitric oxide was fully restored by addition of isoascorbate/ DAD, demonstrating that the HOQNO was not inhibiting the site of nitric oxide reduction at these concentrations.

The cytochrome $b c_{1}$ complex acts as a reductant for cytochrome $c_{2}$ in $R$. capsulatus but the latter cytochrome is not obligatory for nitric oxide reduction because a mutant, MTG4S4, in which the gene for cytochrome $c_{2}$ is specifically deleted was still able to reduce nitric oxide, albeit at a slightly slower rate than the parent strain (Table 2). In $R$. capsulatus MTG4S4 the record of respiration measured by the nitric oxide electrode was monophasic, resembling the parent strain in the presence of acetylene. This is because cytochrome $c_{2}$ has been found to be an obligatory component for nitrous oxide respiration (Richardson et al., 1991) which, as described earlier, accounts for the second phase of the electrode response with cells. The cytochrome $b c_{1}$ complex was still operative in the mutant since myxothiazol was observed to give partial but considerable inhibition (Table 2). Thus the cytochrome $b c_{1}$ complex can reduce one or more components as alternative(s) to cytochrome $c_{2}$, and this (these) component(s) must also be able to accept electrons from the pathway that is independent of the cytochrome $b c_{1}$ complex. As expected from the foregoing results, a mutant, MTGS18, in which both the cytochrome $b c_{1}$ complex and cytochrome $c_{2}$ were absent, was also able to reduce nitric oxide, although at approximately half the specific rate $\left[8 \mathrm{nmol} \mathrm{min}^{-1}(\mathrm{mg}\right.$ protein $)^{-1}$ ] measured for the parent strain grown under the same conditions [i.e. $15 \mathrm{nmol} \mathrm{min}^{-1}(\mathrm{mg} \text { protein })^{-1}$ ]. $R$. capsulatus mutant $\mathrm{H} 123$, which lacks cytochrome $c^{\prime}$ (Hudig et al., 1986), was observed to reduce nitric oxide at a rate $\left[15 \mathrm{nmol} \mathrm{min} \mathrm{m}^{-1}(\mathrm{mg} \text { protein })^{-1}\right]$ that was not attenuated compared to its parent strain $37 \mathrm{~b} 4$. This provides firm evidence that cytochrome $c^{\prime}$ is not obligatory for nitric oxide reduction in $R$. capsulatus. 


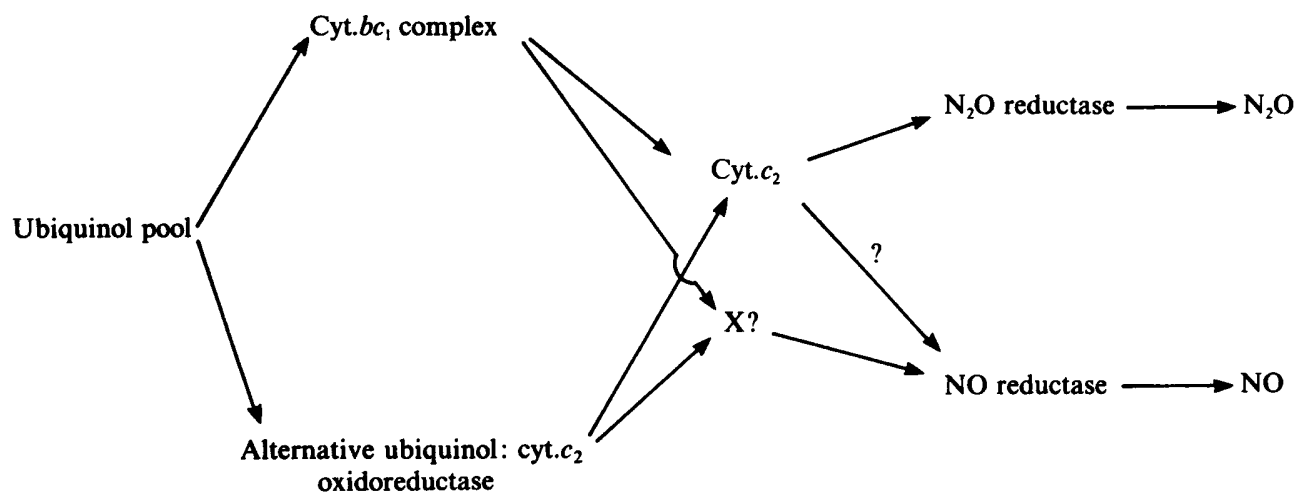

$\mathrm{X}$ is an unknown redox protein

Fig. 3. Proposed scheme for electron transport pathways from ubiquinol to nitric and nitrous oxide reductases in $R$. capsulatus. Two routes for oxidation of ubiquinol are shown on the basis that the absence of the cytochrome $b c_{1}$ complex from mutant MTCBCl does not prevent electron transport to nitric or nitrous oxides, and inhibition of the cytochrome $b c_{1}$ complex by myxothiazol gives only partial attenuation of electron transport in wild-type cells. The molecular nature of the alternative ubiquinol:cytochrome $c_{2}$ oxidoreductase is not known, but it is inhibited by HOQNO (see also Richardson et al., 1989, 1991). Whereas a role for cytochrome $c_{2}$ in nitrous oxide respiration is clearly established (Richardson et al., 1991), its participation in nitric oxide reduction is only by inference (see text). The component $\mathrm{X}$ is an unspecified redox protein that is suggested to mediate between the nitric oxide reductase and either the cytochrome $b c_{1}$ complex, on the basis of the properties of the cytochrome $c_{2}$-deficient mutant (MTG4/S4), or the alternative ubiquinol oxidation pathway, on the basis of the properties of the mutant (MTGS18) that is deficient in both cytochrome $c_{2}$ and the cytochrome $b c_{1}$ complex. The possibility that the latter, or the alternative ubiquinol oxidation pathway, can interact directly with nitric oxide reductase, although unlikely, cannot be totally discounted, hence the '?' signs.

\section{Discussion}

Reduction of nitric oxide is known from observations with Wolinella succinogenes (Payne et al., 1982) not to be restricted to genera of bacteria that carry out all the reactions of denitrification. The present report of nitric oxide reductase activity in many strains of $R$. capsulatus, including a strain, 37b4, that lacks any other reductase activity towards oxy-species of nitrogen, provides a second and striking example.

A very strong case for the presence of a discrete reductase for nitric oxide in $R$. capsulatus can be made on the basis of both it being in a number of strains that lack between them several different redox components and its specific activity in a given strain being comparable with both the rate of nitrous oxide reduction (see e.g. Fig. 1) and oxidase activities. Had the specific nitric oxide reductase activity been orders of magnitude lower than these other activities, serious consideration would have to be given to the possibility that the reduction of nitric oxide represented a side reaction of a reductase with another primary substrate. The extent to which nitric oxide reductase activity is widespread amongst bacteria in general remains to be seen. The finding of a discrete nitric oxide reductase in a denitrifying strain of Rhodobacter sphaeroides (Itoh et al., 1989) and the close relationship of $R$. capsulatus to $R$. sphaeroides suggests that nitric oxide reductase activity may also be common in the many non-denitrifying strains of the latter organism.

The widespread occurrence of nitric oxide reductase activity amongst strains of $R$. capsulatus, and possibly amongst other organisms, should be viewed in the light of the toxicity and abundance of nitric oxide. This gas is a product of microbial nitrification and denitrification (Goretski \& Hollecher, 1988; Carr et al., 1989; Zafiriou et al., 1989; Rende et al., 1989). Furthermore, it is formed during chemical processes such as the decomposition of nitrite in soils and the combustion of fossil fuels (Logan, 1983). Amongst the potentially toxic effects to bacteria of nitric oxide are the inhibition of the enzymes nitrite reductase (cytochrome $c d_{1}$ ) (Carr et al., 1989; Frunzke \& Zumft, 1986; Dhesi \& Timkovich, 1984; Shapleigh et al., 1987), nitrous oxide reductase (Carr et al., 1989; Frunzke \& Zumft, 1986) and bacterial oxidases (Carr \& Ferguson, $1990 b$ ). It has been proposed that cytochrome $c^{\prime}$ may, in effect, act as a scavenger for nitric oxide and thus have a protective function (Yoshimura et al., 1988). This idea remains to be tested, but the present experiments with the $R$. capsulatus strain $\mathrm{H} 123$ do establish that lack of cytochrome $c^{\prime}$ does not prevent electron transport to nitric oxide reductase. At the concentrations of nitric oxide used in the present work electron transport from NADH to nitric oxide was not significantly impaired by loss of the nitric oxide binding capacity of cytochrome $c^{\prime}$. It may be concluded that cytochrome $c^{\prime}$ is not an 
obligatory component of the electron transport system that terminates in nitric oxide reductase.

The retention, with physiological substrates as electron donors, of nitric oxide reductase activity by the $R$. capsulatus mutants MTCBC1 and MTG4/S4, respectively, establishes that neither the cytochrome $b c_{1}$ complex nor cytochrome $c_{2}$ is obligatory for electron transport to nitric oxide. The partial inhibition by myxothiazol in both wild-type cells and the MTG4/S4 mutant shows, however, that electron flow to the nitric oxide reductase can involve the cytochrome $b c_{1}$ complex. The inhibitory effects of myxothiazol on nitric oxide reduction by $R$. capsulatus MTG4/S4 also show that the cytochrome $b c_{1}$ complex must be able to transfer electrons to an acceptor other than cytochrome $c_{2}$. On the basis of the data in the present paper we cannot exclude the possibility that the transfer is directly to the nitric oxide reductase; this would be equivalent to the proposal (Daldal et al., 1986) of a direct transfer of electrons from cytochrome $b c_{1}$ to the reaction centre in MTG4/S4. However, we note that Jones et al. (1990) have recently identified a $c$-type cytochrome that can substitute for cytochrome $c_{2}$ in the role of a donor to the reaction centre. It is conceivable that this component or one similar could act as an electron donor, called ' $\mathrm{X}$ ' here (Fig. 3), to nitric oxide reductase. In this respect, the electron transport pathway to nitric oxide must differ from that to nitrous oxide. Cytochrome $c_{2}$ is obligatory for the latter (Richardson et al., 1991). In contrast, electron transport to both nitrous oxide (Richardson et al., 1989) and, as shown here, nitric oxide, can bypass the cytochrome $b c_{1}$ complex. Fig. 3 summarizes present conclusions (with some being tentative and indicated as such by '?') concerning the electron transport pathway to reductases for nitric and nitrous oxides in $R$. capsulatus. Direct evidence for including cytochrome $c_{2}$ on a path to nitric oxide is not yet available. However, two considerations indicate that it should be included in Fig. 3. First, cytochrome $c_{2}$ is an electron acceptor from the cytochrome $b c_{1}$ complex whose participation in nitric oxide respiration is established in the present paper. Second, a dependence on cytochrome $c_{2}$ of the rate of electron transfer from the cytochrome $b c_{1}$ complex to nitric oxide reductase has been demonstrated for the membranes of the related organism $R$. sphaeroides f.sp. denitrificans (Itoh et al., 1989), and for reasons discussed below it is very probable that the same type of nitric oxide reductase is found in both $R$. capsulatus and $R$. sphaeroides. It is also noteworthy that antimycin, an inhibitor of the cytochrome $b c_{1}$ complex, fails to inhibit completely the reduction of nitric oxide by the latter organism (Shapleigh \& Payne, 1985), indicating that the cytochrome $b c_{1}$ complex may be bypassed by electrons destined for nitric oxide reductase as proposed here for $R$. capsulatus.

DAD is assumed to be unable to act as a direct electron donor to nitric oxide reductase because it is known to be ineffective at donating electrons to the purified nitric oxide reductase of $\boldsymbol{P}$. denitrificans (Carr \& Ferguson, $1990 a$ ), which is a closely related organism. The fact that the nitric oxide reductase of $P$. stutzeri (Heiss et al., 1989) is very similar to the enzyme from $\boldsymbol{P}$. denitrificans (Carr \& Ferguson, $1990 a$; Dermastia et al., 1991) strengthens the case that the same type of nitric oxide reductase is present in $R$. capsulatus and $R$. sphaeroides, organisms that share membership with $P$. denitrificans of the $\alpha$-purple group of bacteria. Nevertheless, in the absence of a detailed molecular characterization of the nitric oxide reductase from $R$. capsulatus, the possibility that DAD might donate directly to a distinct type of nitric oxide reductase cannot be absolutely excluded. The finding that electron transport from isoascorbate plus DAD to nitric oxide did not generate a membrane potential in $R$. capsulatus MT1131, whereas electron flow from either NADH or succinate did so, indicates that nitric oxide is reduced at the same side of the membrane that is the location of cytochrome $c_{2}$, which is generally regarded as an electron acceptor from DAD. Thus if nitric oxide reductase is an integral membrane protein in $R$. capsulatus, as in $P$. stutzeri (Heiss et al., 1989) and $P$. denitrificans (Carr \& Ferguson, 1990a), it cannot either translocate electrons from the periplasmic side of the membrane to the cytoplasmic side or pump protons from the cytoplasm. This description is in agreement with the conclusion of Shapleigh \& Payne (1985) that protons required for the reduction of nitric oxide are taken from the external side of the cytoplasmic membrane in several organisms. This conclusion concerning the lack of proton pumping by nitric oxide reductase is unaffected by the issue of whether electron flow from DAD is direct or mediated by a periplasmic cytochrome.

This work was supported by the SERC through a grant to S. J.F. and a studentship to L.C. B. We thank Dr F. Daldal, H. Hudig, B. Marrs and $\mathrm{J}$. Willison for supplying strains of $R$. capsulatus. The observations reported here are a development of a long-standing joint project on $R$. capsulatus with Dr Baz Jackson.

\section{References}

Balderston, W. L., Sherr, B. F. \& PAyne, W. J. (1976). Blockage by acetylene of nitrous oxide reduction in Pseudomonas perfectomarinus. Applied and Environmental Microbiology 31, 504-508.

Ballard, A. L., McEwan, A. G., Richardson, D. J., Jackson, J. B. \& FergusON, S. J. (1990). Rhodobacter capsulatus strain BK5 possesses a membrane bound respiratory nitrate reductase rather than the periplasmic enzyme found in other strains. Archives of Microbiology 154, 301-303. 
Bell, L. C. \& Ferguson, S. J. (1991). Nitric and nitrous oxide reductases are active under aerobic conditions in cells of Thiosphaera pantotropha. Biochemical Journal 273, 423-427.

Brudvig, G. W., Stevens, T. H. \& Chan, S. I. (1980). Reactions of nitric oxide with cytochrome $c$ oxidase. Biochemistry 19, 5275-5285.

BURNell, J. N., JoHN, P. \& WHATLEY, F. R. (1975). The reversibility of active sulphate transport in membrane vesicles of Paracoccus denitrificans. Biochemical Journal 150, 527-536.

CARR, G. J. \& Ferguson, S. J. (1990a). The nitric oxide reductase of Paracoccus denitrificans. Biochemical Journal 269, 423-429.

CARR, G. J. \& FERGUSON, S. J. (1990b). Nitric oxide formed by nitrite reductase of Paracoccus denitrificans is sufficiently stable to inhibit cytochrome oxidase activity and is reduced by its reductase under aerobic conditions. Biochimica et Biophysica Acta 1017, 57-62.

Carr, G. J., Page, M. D. \& Ferguson, S. J. (1989). The energyconserving nitric oxide reductase system in Paracoccus denitrificans distinction from the nitrite reductase that catalyses synthesis of nitric oxide and evidence from trapping experiments for nitric oxide as a free intermediate during denitrification. European Journal of Biochemistry 179, 683-692.

Daldal, F., Cheng, S., Applebaum, J., Davidson, E. \& Prince, R. C. (1986). Cytochrome $c_{2}$ is not essential for photosynthetic growth of Rhodopseudomonas capsulata. Proceedings of the National Academy of Sciences of the United States of America 83, 2012-2016.

Daldal, F., Davidson, E. \& CHENG, S. (1987). Isolation of the structural genes for the Rieske-Fe-S protein, cytochrome $b$ and cytochrome $c_{1}$, all components of the ubiquinol:cytochrome $c_{2}$ oxidoreductase complex of Rhodopseudomonas capsulata. Journal of Molecular Biology 195, 1-12.

Dermastia, M., TURK, T. \& Hollocuer, T. C. (1991). Nitric oxide reductase - purification from Paracoccus denitrificans with use of a single column and some characteristics. Journal of Biological Chemistry 266, 10899-10905.

DHESI, R. \& TIMKOVICH, R. (1984). Patterns of product inhibition for bacterial nitrite reductase. Biochemical and Biophysical Research Communications 123, 966-972.

Ferguson, S. J., JaCkson, J. B. \& McEwan, A. G. (1987). Anaerobic respiration in the Rhodospirillaceae: characterisation of pathways and evaluation of roles in redox balancing during photosynthesis. FEMS Microbiology Reviews 46, 117-143.

FRUNZKE, K. \& ZUMFT, W. G. (1986). Inhibition of nitrous oxide respiration by nitric oxide in the denitrifying bacterium Pseudomonas perfectomarina. Biochimica et Biophysica Acta 852, 119-125.

GoRETski, J. \& Hollocher, T. C. (1988). Trapping of nitric oxide produced during denitrification by extracellular haemoglobin. Journal of Biological Chemistry 263, 2316-2323.

Heiss, B., FRUNZKE, K . \& ZUMFT, W. G. (1989). Formation of the N-N bond from nitric oxide by a membrane-bound cytochrome $b c$ complex of nitrate-respiring (denitrifying) Pseudomonas stutzeri. Journal of Bacteriology 171, 3288-3297.

Hudig, H., KaUfmanN, N. \& Drews, G. (1986). Respiratory deficient mutants of Rhodopseudomonas capsulata. Archives of Microbiology 145, 378-385.

Itoh, M., Mizukami, S., Matsuura, K. \& Satoh, T. (1989). Involvement of cytochrome $b c_{1}$ complex and cytochrome $c_{2}$ in the electron-transfer pathway for NO reduction in a photodenitrifier, Rhodobacter sphaeroides f.sp. denitrificans. FEBS Letters 244, 81-84.

Jones, M. R., McEwAN, A. G. \& JACKSON, J. B. (1990). The role of $c$-type cytochromes in the photosynthetic electron transport pathway of Rhodobacter capsulatus. Biochimica et Biophysica Acta 1019, 59-66.
Kelly, D. J., Richardson, D. J., Ferguson, S. J. \& Jackson, J. B. (1988). Isolation of transposon Tn 5 insertion mutants of Rhodobacter capsulatus unable to reduce trimethylamine- $N$-oxide and dimethylsulphoxide. Archives of Microbiology 150, 138-144.

LOGAN, J. A. (1983). Nitrogen oxides in the troposphere: global and regional budgets. Geophysical Research Journal 88, 10785-10807.

McEwan, A. G., George, C. L., Ferguson, S. J. \& Jackson, J. B. (1982). A nitrate reductase activity in Rhodopseudomonas capsulata linked to electron transfer and generation of a membrane potential. FEBS Letters 150, 277-280.

McEwan, A. G., Jackson, J. B. \& Ferguson, S. J. (1984). Rationalisation of properties of nitrate reductase in Rhodopseudomonas capsulata. Archives of Microbiology 137, 344-349.

McEwan, A. G., Greenfield, A. J., Wetzstein, H. G., Jackson, J. B. \& Ferguson, S. J. (1985). Nitrous oxide reduction by members of the family Rhodospirillaceae and the nitrous oxide reductase of Rhodopseudomonas capsulata. Journal of Bacteriology 164, 823-830.

MARRS, B. \& GeST, H. (1973). Genetic mutations affecting the respiratory electron-transport system of the photosynthetic bacterium Rhodopseudomonas capsulata. Journal of Bacteriology 114, 1045-1051.

Payne, W. J., Grant, M. A., Shapleigh, J. P. \& Hoffman, P. (1982). Nitrogen oxide reduction in Wolinella succinogenes and Campylobacter species. Journal of Bacteriology 152, 915-918.

RENDE, A., SLEMr, F. \& CONRAD, R. (1989). Microbial production and uptake of nitric oxide in soil. FEMS Microbiology Ecology 62, 221-230.

Richardson, D. J., McEwan, A. G., Jackson, J. B. \& Ferguson, S. J. (1989). Electron transport pathways to nitrous oxide in Rhodobacter species. European Journal of Biochemistry 185, 659-669.

Richardson, D. J., Bell, L. C., McEwan, A. G., Jackson, J. B. \& Ferguson, S. J. (1991). Cytochrome $c_{2}$ is essential for electron transfer to nitrous oxide reductase from physiological substrates in Rhodobacter capsulatus and can act as an electron donor to the reductase in vitro; correlation with photoinhibition studies. European Journal of Biochemistry 199, 677-683.

ShaPleigh, J. P. \& PAYNE, W. J. (1985). Nitric oxide-dependent proton translocation in various denitrifiers. Journal of Bacteriology 163, 837-840.

Shapleigh, J. P., Davies, K. J. P. \& Payne, W. J. (1987). Detergent inhibition of nitric-oxide reductase activity. Biochimica et Biophysica Acta 911, 334-340.

TRUMPOWER, B. L. (1990). Cytrochrome $b c_{1}$ complexes of microorganisms. Microbiological Reviews 54, 101-129.

Weaver, P. F., Wall, J. D. \& Gest, H. (1975). Characterisation of Rhodopseudomonas capsulata. Archives of Microbiology 105, 207216.

Willison, J. C. (1990). Derivatives of Rhodobacter capsulatus strain AD2 cured of their endogenous plasmid are unable to utilize nitrate. FEMS Microbiology Letters 66, 23-28.

YOSHIMURA, T. \& K NOWLES, R. (1976). Acetylene inhibition of nitrous oxide reduction by denitrifying bacteria. Biochemical and Biophysical Research Communications 69, 705-710.

Yoshimura, T., IWASaki, H., ShIDra, S., Nakahara, A. \& MATSUBARA, J. (1988). Nitric oxide complex of cytochrome $c^{\prime}$ in cells of denitrifying bacteria. Journal of Biochemistry 103, 1016-1019.

ZAFIRIOU, O. C., HANLEY, Q. S. \& SNYDER, G. (1989). Nitric oxide and nitrous oxide production and cycling during dissimilatory nitrate reduction by Pseudomonas perfectormarina. Journal of Biological Chemistry 264, 5694-5699. 